Parkin, S., and Coomber, R. (2010). Fluorescent Blue Lights, Injecting Drug Use and Related Health Risk in Public Conveniences: Findings from a Qualitative Study of Micro-Injecting Environments. Health and Place 16, 629-637.

Keywords: fluorescent blue lights, public injecting, public toilets, habitus, symbolic violence, drug use settings, risk environments, harm reduction.

\title{
Abstract
}

This paper presents findings relating to injecting drug users' experiences and opinions of public toilets illuminated with fluorescent blue lights and presents an empirical assessment of the intended deterrent effect of such installations. These findings were obtained from qualitative research located in the south west of England concerning the effects of place on health risk with a sample of 31 drug users with recent experience of 'public' injecting.

Data analysis identified that blue lights deterred less than half the sample interviewed. Furthermore over half $(18 / 31 ; 58 \%)$ of the sample were prepared to inject in conditions specifically designed to deter injecting practice. Of these, 11 respondents were completely undeterred and a further 7 individuals were only partially deterred by blue light environments.

These findings are discussed within the interpretative frameworks of Pierre Bourdieu's theory of habitus and symbolic violence. The authors conclude that fluorescent blue lights contribute towards the development of situated resistance by injecting drug users within a public injecting habitus; a resistance that produces and reproduces drug-related harm and is behaviour that opposes the symbolic violence of harm reduction intervention. The paper concludes with suggestions for theory-driven practical intervention that may seek to disrupt the harmful elements of the public injecting habitus. 


\section{Fluorescent Blue Lights, Injecting Drug Use and Related Health Risk in Public Conveniences: Findings from a Qualitative Study of Micro-Injecting Environments.}

\section{Introduction}

The injecting use of illicit drugs in public settings has prompted a number of official, formal responses on an international basis. Apart from those relating to law enforcement, these responses range from the introduction (or piloting) of services with a harm reduction remit to those with a more preventative agenda. Examples of those seeking to reduce harm may include the installation of street-based syringe vending machines and roving mobile van outlets in areas known to contain public injecting (Islam and Conigrave 2007). Similarly, the introduction of Safer Injecting Facilities (or Drug Consumption Rooms) throughout continental Europe (Hedrich 2004) appears to have mainly been a response to street-based drug injecting and/or open drug markets. Although the latter facilities do not currently exist in the UK, they have been adopted in nations beyond Europe in attempts to reduce drugrelated harm in community settings. Namely, they currently exist as medical and scientific trials respectively in Australia and Canada. In contrast to these interventions with a specific harm reduction concern are those that seek to disperse and/or displace public injecting. Such preventative strategies may include increased policing of drug markets in so-called 'crackdowns' (Cooper et al 2005, Fitzgerald et al 2004, Maher and Dixon 2001); the physical removal of public injecting sites by legitimate force (Parkin and Coomber 2009) or displacement strategies such as blocking, improved fencing, increased surveillance or the installation of motion detector alarm systems (ibid, Rhodes et al 2006). A further mode of drug prevention by dispersal, and the major theme of this paper, concerns the installation of fluorescent blue lights within public conveniences (Hamilton 2000, Flemen 2003, Parkin and Coomber 2009).

Although very different approaches in attempts to address public injecting issues, the dichotomous strategies of harm reduction and drug prevention outlined above, somewhat ironically, appear to have some shared common goals. That is, the core concerns are the reduction of street-based injecting, the protection of public health and the maintenance of community safety. However, harm reduction approaches typically prioritise the development of 'enabling environments' (Moore and Dietze 2005, Rhodes 2002) in attempts to alleviate the situational and structural environments of risk-taking in specific drug-using settings (Rhodes 2009: 91). More succinctly, the focus of such schema is upon challenging environments (and not behaviours) towards reducing drug-related harm. In contrast to the 'enabling environment' concept is that of 'risk environment'. This model, developed and advocated by Rhodes (2002, 2009) contends that drug-related risk and harm is constructed by an interplay of four types of environment (physical, social, economic and policy) at two environmental levels (micro and macro). Accordingly, an analytical synthesis of the subsequent overlap of these constituent structures seeks to provide an understanding of the production and reduction of drug-related harm. Furthermore, Rhodes (2009) contends that the central tenets of the theoretical model aim to re-prioritise the sociality of drug use within public health intervention; in which responsibility for harm shifts focus from individuals towards social and political institutions. This model is further concretised in a demonstration of the 'risk environment' concerning the social and structural production of HIV-risk on a global scale (Rhodes et al 2005). Indeed, 'risk environment' appears to have gained considerable ground and is advocated with increasing regularity within drug-research literature as an explanatory mechanism for drug-related harm (for example, Burris et al 2005, Duff 2009, Fitzgerald 2009, Moore 2004, Moore and Dietze 2005, Strathdee and Bastos 
2002). Similarly, the authors previously demonstrated that the displacement and dispersal of public injecting in an urban setting both establishes and perpetuates particular risk environments. Furthermore, such practice may serve as a precursor to 'micro-spatial structural violence' (Parkin and Coomber 2009: 403) due to the potential for injecting drug users (IDU) to experience actual harm as a consequence of the structural modification of public injecting sites (PIS).

\section{Defining 'Public'}

Throughout this paper we refer to toilet facilities that are located and managed within the public and private sectors and, as such, should be jointly considered 'public' conveniences. In this respect, we follow Kitchin and Law's (2001) definition of 'public' to describe places of citizenship that are socially shared and socially private despite the operational differences that exist within the two sectors. That is, toilets made available by the local authority were typically open access, free of charge and available to all for periods of up to twelve hours per day. Those operated within the private sector were also free of charge and available during the hours of business within the premises concerned. However, those within the latter category were typically exclusive to cash-paying patrons accessing the relevant settings (such as fast food restaurants) and there was the expectation that non-patrons would not casually access these toilets in a manner similar to those within 'high-street' locations (i.e. public sector facilities). This was made apparent with various signs noted during fieldwork that declared, 'These toilets are for customers only'.

In this paper we further develop the themes of risk environment, micro-spatial structural violence and drug-related harm in an analysis of IDU experiences of injecting practice associated with public settings illuminated with fluorescent blue lights (FBL). However, prior to this account it is perhaps necessary to elaborate further upon the function and wider concerns of FBL.

\section{The Fluorescent Blue Light Phenomenon}

The installation of fluorescent blue lights in public conveniences is perhaps a distinctly visible phenomenon in many UK cities, towns and villages. Such lights may be noted typically within public conveniences in a wide variety of amenities; such as travel termini, shopping centres, fast-food restaurants, cinemas and 'high street' toilets. As such, FBL may be installed in facilities that are located within the private and public sectors and premised solely upon relevant stakeholder decisions (Parkin and Coomber 2009).

The function and purpose of such lighting has previously been described (Hamilton 2000, Flemen 2003) as an attempt to deter IDU from accessing the semi-protective and needful amenity afforded by public toilets for the purpose of drug injecting. This deterrent effect is premised upon the decreased and distorted lighting that serves to problematise the visibility of veins (corporeal injecting sites) that render injecting episodes 'more arduous' (Hamilton 2000: 12). This is achieved by an intense, electric-blue ambience created by FBL that may also establish wider, minor visual disorientation amongst individuals entering affected environments - regardless of intent. However, from a harm reduction perspective, such lighting may establish particular risk environments for IDU and has been condemned as initiatives that are 'ill-informed and ill-advised' (Flemen 2003: 3) due to their potential for increasing opportunities for the production of risk behaviour and related hazard. 
Figures 1 and 2 below provide visual data gathered during ethnographic fieldwork that attempt to portray environments lit by such 'manufactured' illumination. (However, the impact of these images is reduced due to the monochrome printing that significantly understates the full 'blue' effect) ${ }^{1}$

Fig 1 here:

Fig 2 here

Figure 1 and 2: Illustrations public conveniences equipped with FBL provided by agencies from the public (above, left) and private (above, right) sectors within the city of Plymouth (UK)

Flemen (ibid) further explains that although such environments may make superficial veins (e.g. those in the forearm) less visible they equally have no deterrent effect upon the body's deeper veins (such as the femoral vein located in the groin). Accordingly, Flemen contends that 'groin injectors' may not necessarily be deterred, or discouraged, by the presence of FBL as such corporeal sites can be located by touch rather than vision. This perhaps raises immediate concerns for advocates of harm reduction who actively discourage groin injecting amongst IDU regardless of setting. For example, a national (UK) drugs information agency stress that groin injecting per se 'should only ever be a last resort' (Lifeline n.d.: 15). Similarly, Preston and Derricot (2006) advise IDU that such practice should be considered 'high-risk' behaviour due to the potential for immediate and long term physical damage to limbs, veins and arteries. Indeed, Flemen (2003) provides further illustrations of the serious medical implications associated with femoral injections; including the risk of infection, abscesses, deep vein thrombosis and injuries resulting from 'missing' veins during drug administration. Accordingly, Flemen infers that the presence of FBL may actually initiate 'last resort' situations as they provide no viable alternative for injecting into more superficial veins. Similarly, the view that groin injecting provides a 'sure shot' effect (Rhodes, Stoneman et al 2006: 166) may also counter the deterrent purpose of FBL upon established and/or novice groin injectors. These concerns are perhaps further problematised by the findings from recent studies that have demonstrated an increase in the normalisation and acceptability of femoral injecting amongst various cohorts of IDU located throughout the UK (Maliphant and Scott 2005, Rhodes et al 2006).

FBL have also received criticism for the wider social concerns that are raised by their presence in public settings. That is to say, facilities containing FBL would appear to stigmatise a particular location; inferring an association with injecting drug use and/or wider social dysfunction. Hamilton (2000) for example, suggests that FBL may instigate a community-wide social unease that connects blue lights with tensions surrounding drugrelated fear and danger and may initiate expectations of violence and disorder. Accordingly, she furthers, such fears and expectations contribute to less functional and cohesive communities as FBL serve to problematise public space and wider sociability. Similar views are echoed by Flemen (2003) who adds that FBL environments may also contribute towards less safe working environments for relevant employees (e.g. toilet attendants) in which tasks are completed less competently (see also Parkin and Coomber 2009). Further concerns are that such settings may problematise access for disabled patrons and that such conditions

\footnotetext{
1 However, readers that may be interested in viewing colour copies of these images should contact the corresponding author.
} 
generally initiate minor physical complaints such as headaches, blurred-vision and sensory discomfort (Hamilton 2000, Parkin and Coomber 2009) regardless of physical dis/ability.

A final concern relates to the actual dispersing effect of FBL and the view that such lighting does not prevent injecting from occurring in more disparate settings adjacent to FBL settings. As we previously noted (Parkin and Coomber 2009) the dispersal effect is one that may establish numerous 'satellite' public injecting sites that are typically smaller and within more secluded areas of drug use. Flemen (2003) notes that the economic costs associated with managing an increased number of PIS established by dispersal become increased (for example, in terms of collecting drug-related litter).

Perhaps the most significant document to critique FBL however is that by the UK government's Department of Environment, Food and Rural Affairs (DEFRA 2005). Although not responsible for determining UK drug policy, this statutory body does provide an advisory role to the Home Office and Department of Health. In its 2005 report on 'Tackling Drug Related Litter', and based on the concerns outlined above regarding the harmful and deleterious effect of FBL, the agency recommended that 'due to the increased risks to users and lack of evidence as to its efficiency, blue lighting should not be used in public toilets to deter drug use' (DEFRA 2005: 36, emphasis added).

Finally, in a previous paper (Parkin and Coomber 2009) to emerge from this research we provide an empirical assessment of Pierre Bourdieu's theory of symbolic violence in relation to the practice of public injecting. This earlier paper was based upon fieldwork conducted with numerous agency representatives directly affected by public injecting issues (and did not include the views and experiences of IDU). Furthermore, these previous findings concluded that the installation of blue lights was considered as one of several modes of tacit social control (i.e. symbolic violence) that sought to deny IDU access to public conveniences based upon an injecting use of drugs, whilst simultaneously adversely affecting the wider population. Furthermore, decisions to install FBL were found to be based upon ad hoc assessments that lacked any evidence of efficacy in deterring drug use. Accordingly, we previously framed these judgements as an illustration of the 'cultural arbitrary by an arbitrary power' (Bourdieu 1977: 19) that simultaneously misrecognised the control and domination asserted upon injecting drug use/rs per se by structural forces. In the following pages we further this stance by situating FBL within Bourdieu's (1977) socio-cultural theory of habitus. However, whereas IDU views were absent in the previous account of symbolic violence, in this paper we provide an empirical assessment of these theoretical concepts that is based exclusively upon the experiences of a sample of current public injectors. This assessment of structure and agency further illustrates the harmful and hazardous consequences of symbolic violence upon a marginalised population (i.e. micro-spatial structural violence) and forms the Discussion section of this paper.

\section{The Study}

The findings described in this paper were obtained from doctoral research located in the city of Plymouth (Devon) on the South West coast of England. This study concerns the effects of place on health risk with specific focus upon injecting drug use in public and semi-public locations (of which FBL settings were only one 'category' of numerous micro-injecting environments identified). The aims of the research were to identify the way in which these settings impact upon injecting-related risk behaviours and to consider the social meaning IDU associate with such places of drug administration. The study was funded with a Collaborative 
Award in Science and Engineering (CASE) provided by the Economic and Social Research Council (ESRC) of Great Britain and Plymouth Drug and Alcohol Action Team (DAAT). Research commenced in October 2006 and concluded in September 2009 with thesis submission. All research was ethically approved by the relevant bodies.

\section{Method}

Although the wider research involved the application of a variety of qualitative methods (including ethnographic observation, observant participation, visual methods), the findings detailed below were obtained primarily from semi-structured interviewing. These interviews took place with 31 current injecting drug users (see below) in one of three settings. These were a 'safer injecting service' (an agency that provides a wide range of drug and alcohol services) and within two amenities available for homeless people (a drop-in centre and a hostel providing temporary accommodation). All interviews were conducted in private rooms to maintain confidentiality and, due to the sensitive nature of the topics discussed, respondents provided verbal informed consent to participate in the research (Coomber 2002). (Further details of respondent recruitment procedures within these agency settings can be found in Parkin and Coomber (2009b)). Similarly, all interviews followed ethical procedures in terms of anonymity, confidentiality and the right to decline answering particular questions or withdraw from interview if necessary.

Topics covered in the semi-structured interview related mainly to respondents' experience of injecting drug use in public and semi-public locations (including toilets, car parks, parkland, toilets and abandoned buildings). Accordingly, questions were categorised into themes such as 'location', 'preparation (of drugs)', 'injecting-technique and hygiene' and 'contact with others'. Due to the open nature of semi-structured interviewing, particular themes and topics may be covered at varying length per individual. Therefore, respondent experiences of FBL were variable, but this was an issue of which all respondents held an opinion (regardless of experience). Accordingly, these views and experiences have been collated and presented in this paper.

Each interview lasted approximately 40 minutes and all were recorded using digital audioequipment. On completion of the interview, all respondents were given a reciprocal cash payment of $£ 10$. Digital interviews were subsequently transcribed verbatim and subject to analysis using a qualitative software package (NVivo 7).

\section{The Sample}

The principal entry criterion for participation in the study was that individuals were a current injector and had injected in a public setting 'within the last month'. These aspects of participation were determined prior to any interview (with a series of 'screening questions') and eventually provided a sample of 31 respondents during a six-month period (FebruaryJune 2008). To summarise the sample; a typical male respondent was aged 34, white (British) and originated from the local area. This person would likely to be currently unemployed, have experience of homelessness and have served at least one prison sentence for drugrelated offences. The average male injecting career was 15 years and heroin was the main drug injected. Similarly, a typical female recruited to the study was aged 30, also unemployed, white (British), from Plymouth and had experience of homelessness. This individual would be more likely to have some experience of sex work as a means of financing drug use. The average injecting career for female respondents was 8 years; in which heroin was also the main drug of choice. 
From these data it is perhaps noteworthy that the sample is perhaps characterised by socioeconomic exclusion and marginality. Indeed, it is further remarkable that the sample shares many socio-economic characteristics and features of individuals involved in public injecting when internationally compared (Darke et al 2001, Green et al 2003, Klee and Morris 1995, McKnight et al 2007, Navarro and Leonard 2004).

\section{Findings}

During the course of fieldwork, a total of 78 public injecting sites (PIS) were identified throughout the city and its environs. Indeed, it was further possible to 'map' these sites into one of five geographic zones that were arranged concentrically around the city's centrepoint. The social geography and economic conditions typifying each of these zones has been documented elsewhere (Parkin 2009) in which Zone 1 contains the central business/retail district; Zone 2 consists of low budget, 'economy' retail outlets and segregates the residential/business/developmental properties of Zone 3 from Zone 1 . The fourth zone comprises almost exclusively of housing stock (within the public and private sector) whereas Zone 5 was typified by suburbs surrounding the city that were characterised by either affluence or deprivation.

Of the 78 PIS identified, 6 sites contained FBL. The settings were all public conveniences that were dispersed throughout Zones 1, 2 and 5 described above (Zone 1 = 3, Zone $2=2$ and Zone $5=1$ ). More specifically, these 6 locations comprised of 12 units (i.e. 5 male toilets 5 female, 1 disabled toilet and 1 unisex). Furthermore, 8 of these units were located within the private sector (fast-food restaurants, a supermarket and a high street department store). The remaining 4 units were located in facilities operated and managed by the local authority/municipal council (Plymouth City Council).

Data analysis of respondents' experience of these FBL settings in Plymouth identified several themes of commonality throughout the sample. These themes concerned 'knowledge', 'opinion', 'deterrent effect', 'non-deterrent effect', 'femoral-injecting' and 'preparedness to inject'. Each of these matters are summarised and presented below.

\section{Knowledge of Blue Lights}

All 31 respondents were familiar with the blue light phenomenon and all could name at least one location in Plymouth that had such lighting installed. Although not all respondents had injected under blue lights, this local familiarity appeared integral with regard to knowing where and when to go to preferred injecting locations. Therefore, those that did not prefer to inject in FBL toilets were familiar with such settings that should be avoided. Those that could identify more settings equipped with FBL were also more likely to inject within such environments.

Knowledge also pertains to the actual function of FBL and all but one respondent believed that they were installed specifically to deter injecting drug use from occurring within. Remarks such as 'to stop drug use', to make 'injecting more difficult' 'so that you can't see your veins properly' typified this awareness of function.

More specific awareness was noted in comments relating to the health of individual respondent's veins. Those with more 'healthy veins' believed that FBL were ineffective in visibly locating veins; whereas those with 'collapsed veins' stated that they were an effective 
device for reducing visibility. However, for reasons that will emerge below, FBL were typically regarded as 'pathetic' or 'rubbish', or as an initiative that 'doesn't work' and 'doesn't stop' IDU from using toilets equipped with blue lights. For example, the assumed relationship between healthy veins and an inadequate deterrent system of can be noted in the following statement:

... if you're like me and you've got good veins and you know where to go exactly in your arm to get a vein; they don't work. But people who struggle to get veins and can't see their veins and don't know where they are; they work.

(R014, Male, aged 29)

Opinion of Blue Lights

Regardless of whether individual respondents accessed toilets with FBL for injecting purposes or not, each of the sample held opinions of an intervention that was considered a feature designed to address an aspect of their particular lifestyle. Accordingly, most of the sample's opinion of FBL provided remarks of a 'drug-related' nature and the impact they may have upon drug use and drug using. For example:

I don't think they're a good idea at all. Really. I think if people are gonna have a hit, they'll do it anyway, you know? If that's the only place they can go, they'll still have a go at doing it in there. If it makes it harder for them to get it, then you're just doing that bloke no favours whatsoever at the end of the day. He's still in there having a hit ain't he? And all you're doing is fucking his arms up for him.

(R017, Male, Aged 34)

Similarly:

(Fluorescent blue lights are) an annoyance. A nuisance. Personally I think it's been a good invention for whoever come up with it here. But for us, it has created a lot of stresses because we have to find other places. And you can regularly use the same toilet and then they come and you find the lighting and you can't use it anymore.

(R026, Male, Aged 44)

Other respondents voiced opinions of a wider, non-drug-related nature. Such views related more to the 'sensory' aspects of FBL rather than the intended dispersal effect. For example:

... for people that ain't even on drugs, I don't think it's fair because like, myself I have epilepsy, and lights like that ... I don't get on with them. So I don't get on with flashing lights either. So ... I just think for people that's got epilepsy and that, I don’t think it's fair.

(R012, Female, Aged 20)

Other female respondents made similar remarks regarding FBL effects upon the mobility of the elderly, those with poor vision or described headaches caused by 'horrible' environments that 'hurt (my) eyes'.

Over one-fifth $(7 / 31 ; 22.5 \%)$ of the sample also believed that blue lights were a 'good idea' and were a necessary intervention to deter drug use (amongst IDU) and thus maintain the 
'safety' of the general public (from drugs per se). For these individuals, there was a sense of resigned acceptance that an IDU lifestyle had generated an intervention that affected the wider community (regardless of whether they were considered effective or not). For example:

... it's not very good going in toilets and it's really dark blue, ain't it? But it's things that gotta be done, I guess, to stop people from (injecting there). But in a way it don’t work 'cos you can still get your vein.

(R012, Female, Aged 20)

Many of these opinions would appear to support previous anecdotal evidence (Hamilton 2000) and harm reduction advice (Flemen 2003) regarding the criticisms of FBL outlined above. Similarly, the latter views regarding an acceptance of blue light environments may further illustrate the symbolic violence of FBL (Parkin and Coomber 2009). Namely, symbolic violence consolidates power and control upon the dominated due to the legitimised acceptance and recognition of 'not only the way things are, but as the way they ought to be' (Jenkins 2002: 156).

\section{Deterrent Effect of Blue Lights}

As noted above, blue light environments are designed to deter and discourage injecting drug use from taking place therein. For less than half of the sample $(13 / 31 ; 42 \%)$ in the current setting, FBL did indeed have this effect upon injecting drug use. That is, knowledge of public conveniences equipped with FBL was often sufficient to prevent access due to an awareness of the 'problematising' effect upon injecting practice. Remarks such as 'they stop me/users' from going there' and were venues 'to be avoided like the plague' typified such aversion strategies. Similarly, others claimed never to have tried injecting under such conditions; not necessarily because of the lighting but due to a preference for other PIS. However, those that had never injected in blue light environments were also sceptical of the assumed deterrent effect. This may be noted in the following comments that infer an assumed ability to successfully administer drugs under such circumstances:

They're annoying, they hurt your eyes. But I reckon I could still probably do it (inject) even with them.

$$
\text { (R001, Female, Aged 21) }
$$

I've never done it in there, but I've been told, 'cos my boyfriend's ... pinned up there, that it don't work. It's supposed to stop ya from getting your vein but he says it don't stop ya getting a vein.

$$
\text { (R012, Female, Aged 20) }
$$

A further deterrent effect was the actual prevention of drug use within public toilets; but was activity that was subsequently dispersed to other settings nearby. Dispersal tended to involve respondents relocating to other public injecting sites known within the IDU fraternity and were typically situated within the immediate vicinity of a facility equipped with FBL. As a result of this dispersal process, the need and immediacy to inject may become increased (especially if related to withdrawal symptoms). The consequences of dispersal by FBL when affecting such need is perhaps evident in the following comment:

And the other experience is that you can't use there. And then you end up using in somebody's garden, somebody's alley or somebody's car park or breaking into 
somewhere just to find another place; which is usually a public place and in a public place. The biggest difficulty is that you just lose patience ... and you don't care. You're gonna end up doing something stupid or careless, you rush and end up with deep vein thrombosis or shooting maybe in the wrong - instead of the vein, the arteries.

(R026, Male, Aged 44)

For others $(7 / 31 ; 23 \%)$, FBL had only a partial deterrent effect and, instead, tended to modify the way in which drugs were used. That is, FBL did not prevent drug use from occurring within, but instead influenced alternative strategies that sought to counter-act the deterrent effect. For example, one respondent believed that blue lights made the preparation (rather than the injection) of drugs more difficult (with specific reference to the 'cooking' of heroin in toilet cubicles). However, a response to these difficulties was for this individual to pre-prepare drug solute in a nearby setting and subsequently enter a blue light environment for administration purposes only.

Similarly, a further adaptation to FBL involved the assistance of peers to provide injections under blue light conditions; as the following extract illustrates:

I couldn't do it, it's hard to see actually, with the lights, but I still done it. (My boyfriend) asked me to go and get some water; I went to get some water and then he got me and he done himself and then we left. (He) had to go in my neck ... (because) he can feel (the vein) can't he?

(R023, Female, Aged 37)

Non-Deterrent Effect of Blue Lights

However, over one third (11/31, 35\%) of the sample overtly resisted the deterrent effect of FBL and stated that they had previously injected under such conditions; seemingly without problem or consequence. Furthermore, they stated they would continue to do so, as they did not consider them to be a deterrent to their own injecting practice. Such views were explicated with comments such as 'they are no problem for me', or 'they don't bother me'. Instead, many of these respondents described an assumed adept injecting ability and sufficient intimate knowledge of their bodies that, when combined, gave confidence to inject under problematic environmental conditions. These respondents were equally able to describe the differences between veins and arteries and were conversant in the different blood colour from these respective points, as well hazards associated with artery injection. For example:

... (blue lights) don’t stop you, you can still get your vein ... bang ... draw back ... and you can still (inject) .... Cos if you're drawing back an' (the blood is) black, you can still get yourself really.

(R030, Male, Aged 23)

Similarly:

I can still do it under fluorescent lights, yeah. It's not a problem. I know some people that can't. ... They can't see their veins or whatever, they don't show up or something. I know (the lighting effect) makes the blood a funny colour, you know what I mean? I don't suppose you can tell if its artery blood or vein blood. ... Artery blood is very orange-pinky, a lot lighter and vein blood is darker. 
As such, various strategies were employed towards countering the blue-lights' deterrent effect. For example some respondents attempted to get very close to the actual light believing this improved visibility and yet others stated they could successfully inject by 'feeling out' and 'rolling veins' between fingers. This latter strategy appeared popular amongst those that considered their veins to be 'healthy' (or 'fat') and had not damaged as a result of overuse. Such assumed skilled injecting practice and associated knowledge can perhaps be illustrated with the following:

I'd say (the light) stops $95 \%$ of (drug users), but like I say, I'm one of that 5\% who can ... basically get me veins with me eyes closed.

(R014, Male, Aged 29, emphasis added)

A further response was to use alternative corporeal injecting sites that could be accessed with the assistance of wall-mounted mirrors within the toilets concerned. For example, one respondent (seeking recovery) recalled previous injecting episodes in toilets with blue lights as such:

(I would be) ... looking in the mirror, blowing my neck up and stuff like that. Using the mirror to blow the veins up so I could see it and then just dig it in my neck. I used to have this thing about, well, I wouldn't go into my groin. Because I know people that was going in their groin and they'd lost their legs and stuff like that. So I used to do it healthily! An' stick it in me neck!! (Emphasising irony).

(R029, Male, Aged 49)

Yet another response to countering FBL was a preference for injecting into the femoral vein (groin injecting) as intimated in the previous extract. This issue is presented in further detail immediately below.

These collected adaptations to blue light environments appeared to be a specific skill held by more experienced respondents, (i.e. those with longer injecting histories amongst the sample), who each claimed injecting proficiency within a 'manufactured' environment purposely designed to problematise injecting drug use. Indeed, this adaptation may be further demonstrated by the actions of one respondent who, paradoxically, selected blue light environments for injecting on the basis of their dispersing intent. Such motivations were premised on the avoidance of detection by police officers and subsequently afforded protection from arrest and/or questioning. Namely:

I think if I wanted to go into a toilet now, that's one of the ones I would go in. ... 'Cos police probably think you wouldn't be using a toilet like that.

(R006, Male, Aged 32)

Femoral Injecting and Fluorescent Blue Lights

A further non-deterrent effect of FBL related to individual preferences for injecting into the femoral vein (groin). This was not necessarily a specific adaptation to environmental circumstances, but was typically a continuation of preferred and already established injecting practice amongst those concerned. As such, these individuals did not consider FBL as a deterrent to injecting technique due to the aforementioned reliance upon touch rather than 
vision. This is perhaps evident in the following rationale in which a second respondent frames injecting under FBL conditions in the context of 'blindness' (see above) and perhaps emphasises the sensory shift from vision to tactility:

... you can still inject (in blue light toilets) if someone's got good veins; like fat veins on their arms, you can do it. Whereas for me, down there (groin), I don't need to see it. Obviously I know where I'm going, so I could do it blindfolded if I had to. No problem.

(R004, Male, Aged 29, emphasis added)

As noted above, 'groin injectors' also appeared cognisant of pre-existing risks and harms associated with femoral administration. This was made more explicit when discussing injecting episodes within blue light environments. Namely:

You need to know (about the risks), especially if you go into your groin. You need to know that. Cos if you inject into your artery, it bloody hurts! But no, them lights, they don't affect me at all. I can go into them and have it 'cos I use my groin.

(R017, Male, Aged 34)

\section{Preparedness to Inject under Blue Lights}

Based on this analysis of 31 respondents' views and experiences of FBL, over half (18/31; $58 \%$ ) of the sample were prepared to inject in conditions specifically designed to deter injecting practice. Of these, 11 respondents were completely undeterred by blue lights, whereas a further 7 individuals were only partially deterred by FBL (as they developed alternative injecting strategies that were completed alone or with others). Furthermore, of those undeterred by FBL, there appeared to be a collective ambivalence to the blue light phenomenon and they did not perceive this as problematising injecting technique and/or practice. Accordingly, for all 18 individuals, there was also some indifference to the widerrisks associated not only with FBL, but towards drug injecting per se. This is perhaps reflected in the following view in which the respondent describes lowered priority to drugrelated hazard in blue light settings.

... you see the terrible thing is, is that you never think that you're gonna overdose, an' I've gone in there for 2 seconds and I know I'm gonna come out again and carry on. But I suppose there's other people that don't come out innit? 'Cos you never think it's gonna happen to you. You're always just gonna go in and you are coming out again.

(R022, Female, Aged 32)

Furthermore, the general preparedness to inject in FBL settings, as reported by the sample, appears to be premised upon individual experience (i.e. longer injecting careers) or through a process of 'trial and error'. That is, the numerous accounts of successful injecting episodes, conducted 'without looking' or 'knowing where my veins are' perhaps reveal an assumed intimacy and skilled knowledge of body awareness and injecting to declare such proficiency. Similarly, views such as the following perhaps equally indicate a process of becoming more proficient via a process of 'experimentation'. 
(s)ome (fast food restaurants) use these lights. I attempted there and I only managed to inject because I knew by feeling the vein that it was there. But actually, I could not see it.

(R026, Male, Aged 44)

Well ... I'd heard about it and I'd never even seen it, then I walked in and I thought 'oh, they've got blue lights in here I wonder if I am gonna be able to do it'. And I thought 'ahh ... yeah' (expressing hesitancy and false bravado).

(R022, Female, Aged 32 recalling her first injection in FBL toilets)

Regardless of individual injecting experience or proficiency, other respondents stated that blue light toilets had on occasion provided the nearest available setting for immediate drug administration. Such views of opportunistic access and urgent drug use in hazardous environments were typically related to addressing withdrawal symptoms (or 'feeling sick') or as a response to homelessness (or 'having no other place to go'). Indeed, experiences such as these effectively reflect the 'situational necessities' of public injecting previously described by Rhodes et al (2007: 276), in which IDU may appropriate PIS as a result of drug dependency and/or insecure housing arrangements.

Finally, it is perhaps noteworthy that there was some degree of doubt expressed regarding the intended deterrent effect amongst those that had never injected under FBL. These views were typically informed by the experiences of injecting peers and/or intimate partners. Accordingly, one may speculate that this disbelief when coupled with positive, informal peer advice may influence a preparedness to engage with FBL environments at a later date.

\section{Discussion: Fluorescent Blue Lights, Social Theory and Harm Reduction}

In a previous paper concerning statutory responses to public injecting (Parkin and Coomber 2009), the dispersal effect of the blue light phenomenon was interpreted as an empirical illustration of Bourdieu's theory of symbolic violence. This was due to a specific design that is intended to socially control a particular, marginalised, population (IDU) and is premised upon subjective decisions by those in positions of power and authority. As noted in this paper however, the dispersal and deterrent effect of FBL appears to have been successful amongst less than half the respondent sample interviewed in this research. For these individuals, the symbolic violence of blue light dispersal (i.e. tacit control and compliance) appears to have been a success.

However, more than half of the sample articulated a 'situated resistance' (Parkin 2009: 285) to the deterrent effect of FBL and expressed a continued preparedness to inject in potentially hazardous environments. Although findings such as this may thus appear contrary to the aforementioned theory of symbolic violence - or at least a wholly effective example - with closer analysis and further reference to Bourdieu's (1977) theory of habitus, these findings may actually consolidate the earlier view of symbolic violence.

According to Bourdieu $(1977,1990)$ individual agency is shaped and organised by external forces that unconsciously determine daily practice and behaviour. This relationship defines habitus; and may be considered, more simply, as the way in which individuals naturalise their daily conduct within social situations as a result of particular social influences and interactions. The habitus of public injecting/injectors involves IDU relationships with structural organisations that seek to displace, disperse, arrest and criminalise drug using 
behaviour by overt and covert measures. The behavioural and physical response by IDU to such attempts of continued control and domination may be one of situated resistance as a form of logical practice (Parkin 2009). As such, resistance may take the form of appropriating settings (such as public conveniences) for the rapid ingestion of drugs whilst avoiding arrest and/or detection. In this manner, Bourdieu's habitus concept converges with Foucauldian discourse in that, 'like power, resistance is multiple and can be integrated in global strategies' (Foucault 1980: 142). Accordingly, the public injecting habitus is one structured and characterised by IDU resistance to environments that attempt to problematise daily (injecting) practice.

The control-resistance nexus portrayed throughout this paper perhaps further demonstrates the symbolic violence of harm reduction as noted by other researchers concerned with public injecting and homelessness (Bourgois et al 1997, Bourgois and Schonberg 2009). That is, harm reduction intervention aimed at providing safer injecting technique (i.e. tacit social control to safeguard public health) may be detached from the social and physical realities of street-based drug use. Namely, the expectations of IDU behaviour envisaged by health commissioners and/or practitioners may represent an entirely different habitus to those that choose to inject in public settings. It is for these reasons that Bourgois and Schonberg (2009) consider harm reduction as a philosophy that may resonate more with members of the middle class, and simultaneously alienate those more marginalised by socio-economic deprivation. Indeed, these views of 'alienation' and service detachment may be demonstrated in decisions by IDU in the present setting to peer-inject, administer drugs in the femoral vein and/or rely on touch rather than vision when injecting drugs in public settings. Each of these responses may be interpreted as a habitus of resistance to the structural constraints imposed by FBL and an opposition to harm reduction advice that fails to adequately consider the situated necessity and situated resistance of street-based injecting. However, this naturalised necessityresistance arguably generates a further feature of the public injecting habitus; namely the acceptance, participation and normalisation of existing injecting-related risk-taking behaviour. In short, risks are amplified as a result of structurally influenced resistance strategies and are risks that may affect the health of individual IDU and, potentially, that of the wider population (i.e. public health).

FBL in public conveniences may problematise health and well being of IDU as they create environments in which injecting drug use becomes premised upon tactility rather than vision. In such circumstances, drug users (as noted above) literally can not see where they are injecting and thus establish conditions that are antithetical to the hygienic administration of drugs. Similarly, blue light environments provide opportunities for the continuation (and perhaps the initiation) of injecting into the femoral vein (groin). As with the above concern, groin injecting may be premised upon touch, requiring longer needles to reach deeper veins and has been considered as a site of 'last resort' (Lifeline, n.d.: 15) regardless of environmental setting. However, the impaired visionary effects of FBL is that they establish 'last resort' conditions and may initiate groin injecting in times of urgency and need (for example, when experiencing withdrawal symptoms).

Further harmful effects of FBL influenced by IDU resistance strategies include the reported adaptations to countering reduced lighting within such settings. These may include the use of mirrors for injecting into bodily sites (thus providing an inappropriate 'reflected perspective' of injecting technique that may further encourage rushed administration to avoid non-drug users witnessing drug using episodes within a public setting). Similarly, the practice of peer 
assisted injection raises not only immediate concerns regarding sharing paraphernalia and proficient injecting technique, but also those concerning the transmission of blood borne virus (hepatitis, HIV) via unhygienic physical contact. This is perhaps a concern given that such environments generate reliance upon touch when injecting as a consequence of impaired vision; accordingly, physical contact with blood when injecting others may similarly go unnoticed.

Related to the latter point are concerns regarding individual experience of 'successful' injecting episodes under FBL. As noted above, reports of these experiences within drug user networks have cast doubt in the minds of those that have never injected in such blue light environments. Positive accounts of FBL injecting episodes portrayed by IDU peers may initiate similar practice and is experience that has potential to further re/produce hazard within the public injecting habitus.

\section{Disrupting the habitus}

Kitchin and Law have previously noted that the provision of public toilets in Western societies has become 'an accepted demand on the state' (2001: 288) in recognition of the need to establish private places within public space for intimate practice. Such provision, they add, has its origins during the mid-nineteenth century and was associated with public health reform and improved urban sanitation. In contemporary British society, public toilets maintain this public health value whilst simultaneously provide a continued tradition of free access to basic, essential, amenity for those without secure accommodation and/or rough sleepers. As several have previously noted (Flemen 2003, Hopper 1991) public conveniences provide opportunistic 'survival niches' (Hopper 1991: 163) for the socio-economic marginalised and create temporary opportunities for personal health care and immediate hygiene. Similarly, the use of public toilets for injecting drug use has been previously acknowledged within the literature (Fitzgerald et al 2004, Hamilton 2000, Parkin and Coomber 2009, Rhodes et al 2006). However, although conceding that this represents a deviation from the designated function of public conveniences, drug-related harm may also be temporarily reduced in such settings. This is due to the privacy, sanitation and controlled environment they provide to IDU (Parkin and Coomber 2009) in which the co-presence of others may provide an unofficial safety-net in the event of drug-related hazard, such as overdose (Dovey et al 2001). The use of toilets for such purposes has been further described as not ideal conditions for injecting purposes; but from an IDU health perspective they do, at least, provide less harmful settings until more viable initiatives become available (Flemen 2003). FBL however, problematise each and every one of these functions of public toilets; from an individual and a wider public health perspective. Indeed, FBL would appear to not only contribute towards micro-spatial structural violence, but also seem to influence IDU in becoming complicit in any injecting-related harm.

Based on the above interpretation of FBL we further question the legitimacy of such equipment within any public convenience. This view is premised on the conviction that blue lights do not appear to serve the interests of anybody. That is, the general public does not appear to benefit (as a result experiencing impaired vision and other physical discomfort); those employed in such settings equally do not benefit (for similar reasons) and, from the evidence above, the intended audience of FBL do not benefit. Furthermore, whether located in the private or public sectors, relevant businesses would presumably not profit from FBL as they may inadvertently stigmatise a particular setting. Finally, the relevant local authorities (municipal councils) would equally not benefit from any increased costs involved in 
collecting drug-related litter from adjacent settings as a consequence of dispersed drug use. Accordingly, following this lack of benefit and profit it is perhaps a fair assumption to suggest that those with the most to gain from such equipment are only those responsible for their manufacture and production. Furthermore, such manufacturers would appear to be capitalising on a false promise of deterrence and profiting from the potential harm they may initiate.

Instead, we advocate that health practitioners and advocates of harm reduction reconsider the effects of place on health risk from the Bourdieusian perspectives outlined in this paper. Such an appraisal would essentially aim to disrupt the structural and structuring conditions that contribute towards the public injecting habitus and attempt to counter IDU resistance with more enabling, realistic and inclusive interventions aimed at public injecting/injectors. This disruption of habitus could be initiated with an immediate application of previous recommendations (DEFRA 2005) that categorically state FBL should not be installed in public conveniences. We further add that such lighting perpetuates particular risk environments and, arguably, FBL serve to amplify existing risks associated with injecting drug use per se. Accordingly, we further suggest that consideration should be given towards transforming public toilets to more 'enabling environments' that reduce drug-related harm and protect public health. Such a transition does not require radical, or unique, modes of intervention. For example, as Flemen (2003) previously notes, blue lighting may be replaced by appropriately secured sharps bins; perhaps complemented by syringe vending machines (Islam and Conigrave 2007) in order to minimise opportunities for 'recycling' used equipment. Furthermore, employees within public toilets may be given appropriate training in drug issues (handling and disposing of used equipment, recognising overdose and appropriate resuscitation techniques). Indeed, relatively low-cost interventions such as these may significantly restructure particular risk environments and suitably disrupt the harmful elements of the public injecting habitus - until the option of Safer Injecting Facilities becomes a more politically expedient alternative in UK settings.

However, despite these recommendations, the actual challenge surrounding the FBL phenomenon lies in the ability of health practitioners to effectively convince those responsible for managing blue light environments that they are harmful and hazardous to IDU and also counter-productive to a wider public health. Similarly, harm reduction practitioners perhaps need to recognise the symbolic violence of unrealistic expectations concerning injecting practice within environments that may re/produce 'destructive subjectivities' (Bourgois and Schonberg 2009; 19) within IDU populations.

\section{Disclaimer/Acknowledgements}

The views expressed in this paper are those of the authors and do not necessarily represent those of the University of Plymouth or the bodies responsible for funding this research. The authors declare no conflict of interest and would also like to thank the two anonymous reviewers that provided constructive and informative comments on this paper. 


\section{References}

Bourdieu, P. 1977. Outline of a theory of practice. Cambridge University Press, Cambridge.

Bourdieu, P. 1990. The logic of practice. Polity Press, Cambridge.

Bourgois, P., Lettiere, M. and Quesada, J. 1997. Social misery and the sanctions of substance abuse: Confronting HIV risk amongst homeless heroin addicts in San Francisco. Social Problems, 44, (2) 155-173.

Bourgois, P. and Schonberg, J. 2009. Righteous dopefiend. University of California Press, Berkeley.

Burris, S., Blankenship, K. M., Donoghoe, M., Sherman, S., Vernick, J. S., Case, P., Lazzarini, Z. and Koester, S. 2004. Addressing the 'risk environment' for injection drug users: The mysterious case of the missing cop. The Millbank Quarterly, 82, (1) 125-56.

Coomber, R. 2002. 'Signing your life away? Why research ethics committees (REC) shouldn't always require written confirmation that participants in research have been informed of the aims of a study and their rights: the case of criminal populations. (commentary)'. Sociological Research Online. 7, 1.

http://www.socresonline.org.uk/7/1/coomber.html (Accessed August 2009)

Cooper, H., Moore, L., Gruskin, S. and Krieger, N. 2005. The impact of a police crackdown on drug injectors' ability to practice harm reduction: A qualitative study. Social Science and Medicine, 61, 673-684.

Darke, S., Kaye, S. and Ross, J. 2001. Geographical injecting locations among injecting drug users in Sydney, Australia. Addiction, 96, 241-246.

DEFRA 2005. Tackling drug related litter: Guidance and good practice. Department for Environment, Food and Rural Affairs, London.

Dovey, K., Fitzgerald, J. and Choi, Y. 2001. Safety becomes danger: Dilemmas of drug-use in public space. Health and Place, 7, 319-331.

Duff, C. 2009. The drifting city; the role of affect and repair in the development of 'enabling environments'. International Journal of Drug Policy, 20, 202-208.

Fitzgerald, J., Dovey, K., Dietze, P. and Rumbold, G. 2004. Health outcomes and quasisupervised settings for street injecting drug use. International Journal of Drug Policy, 15, 247 - 257.

Fitzgerald, J. L. 2009. Mapping the experience of drug dealing risk environments: An ethnographic case study. International Journal of Drug Policy, 20, 261-269.

Flemen, K. 2003. Blue light blues: The use of blue lights as a deterrent to injecting. www.ixion.demon.co.uk. 
Foucault, M. 1980. Power-knowledge: Selected interviews and other writings, 1972-1977. Harvester Press, Brighton.

Green, T., Hankins, C., Palmer, D., Boivin, J.-F. and Platt, R. 2003. Ascertaining the need for a safer injecting facility (SIF): The burden of public injecting in Montréal, Canada. Journal of Drug Issues, (Summer) 713-732.

Hamilton, M. 2000. 'Blue loos': Blue lights in public toilets. VicHealth Letter, 13, (Autumn) 12-13.

http://www.vichealth.vic.gov.au/ /media/ResourceCentre/PublicationsandResources/Letter/V icHealthLetter13_00.ashx (Accessed August 2009)

Hedrich, D. 2004. European report on drug consumption rooms. European Monitoring Centre for Drugs and Drug Addiction, Luxemburg.

Hopper, K. 1991. Symptoms, survival and the redefinition of public space: A feasibility study of homeless people at a metropolitan airport. Urban Anthropology, 20, (2) 155-175.

Islam, M. M. and Conigrave, K. M. 2007. Assessing the role of syringe dispensing machines and mobile van outlets in reaching hard-to-reach and high-risk groups of injecting drug users (idus): A review.

Harm Reduction Journal, 4, (1) http://www.harmreductionjournal.com/content/4/1/14. (Accessed August 2009)

Jenkins, R. 2002 Pierre Boudieu. Routledge, London.

Kitchin, R. and Law, R. 2001. The socio-spatial construction of (in)accessible public toilets. Urban Studies, 38, (2) 287-298.

Klee, H. and Morris, J. 1995. Factors that characterize street injectors. Addiction, 90, 837841.

Lifeline n.d. Going in the groin: Injecting in the femoral vein. Lifeline Publications, Manchester.

Maher, L. and Dixon, D. 2001. The cost of crackdowns: Policing Cabramatta's heroin market. Current Issues in Criminal justice, 13, (1) 5-22.

Maliphant, J. and Scott, J. 2005. Use of the femoral vein ('groin injecting') by a sample of needle exchange clients in Bristol, UK. Harm Reduction Journal, 2, (6)

http://www.pubmedcentral.nih.gov/articlerender.fcgi?artid=1090606

(Accessed August 2009)

McKnight, I., Maas, B., Wood, E., Tyndall, M. W., Small, W., Lai, C., Montaner, J. S. G. and Kerr, T. 2007. Factors associated with public injecting among users of Vancouver's supervised injecting facility. American Journal of Drug and Alcohol Abuse, 33, (2) 319-326.

Moore, D. 2004. Governing street-based injecting drug users: A critique of heroin overdose in Australia. Social Science and Medicine, 59, 1547-1557. 
Moore, D. and Dietze, P. 2005. Enabling environments and the reduction of drug-related harm: Re-framing Australian policy and practice. Drug and Alcohol Review, 24, 275-284.

Navarro, C. and Leonard, L. 2004. Prevalence and factors related to public injecting in Ottawa, Canada: Implications for the development of a trial safer injecting facility. International Journal of Drug Policy, 15, 275 - 284.

Parkin, S. 2009. The effects of place on health risk: A qualitative study of micro-injecting environments. PhD thesis, University of Plymouth.

Parkin, S. and Coomber, R. 2009. Public injecting and symbolic violence. Addiction Research and Theory, 17, (4) 390-405.

Parkin, S. and Coomber, R. 2009b. 'Informal sorter houses': A qualitative insight of the 'shooting gallery' phenomenon in a UK setting. Health and Place, 15, 981-989

PCC 2008. Needle bin usage. Street Services Department, Plymouth City Council, Plymouth.

Preston, A. and Derricot, J. 2006. The safer injecting handbook (sixth edition). Exchange Supplies, Dorchester.

Rhodes, T. 2002. The 'risk environment': A framework for understanding and reducing drugrelated harm. International Journal of Drug Policy, 13, 85-94.

Rhodes, T. 2009. Risk environments and drug harms: A social science for harm reduction approach. International Journal of Drug Policy, 20, 193-201.

Rhodes, T., Kimber, J., Small, W., Fitzgerald, J., Kerr, T., Hickman, M. and Holloway, G. 2006. Public injecting and the need for 'safer environment interventions' in the reduction of drug-related harm. Addiction, 101, (10) 1384-1393.

Rhodes, T., Singer, M., Bourgois, P., Friedman, S. R. and Strathdee, S. A. 2005. The social structural production of HIV risk among injecting drug users. Social Science and Medicine, 61, 1026-1044.

Rhodes, T., Stoneman, A., Hope, V., Hunt, N., Martin, A. and Judd, A. 2006. Groin injecting in the context of crack cocaine and homelessness: From 'risk boundary' to 'acceptable risk'? International Journal of Drug Policy, 17, 164-170.

Strathdee, S. A. and Bastos, F. I. 2002. From risk environments to safe havens: Understanding context in the development of harm reduction interventions for drug users. International Journal of Drug Policy, 13, 81-83. 